\title{
Ethical and Economic Perspectives on Global Health Interventions
}

Forthcoming in Garrett Brown and Gavin Yamey (eds.), The Handbook of Global Health Policy. Wiley Blackwell.

\author{
Sonia Bhalotra and Thomas Pogge
}

\begin{abstract}
We suggest how contemporary global institutions shaping the development, pricing and distribution of vaccines and drugs may be modified to deliver large improvements in health. To support a justice argument for such modification, we show how the current global economic order may contribute to perpetuating poverty and poor health in less-developed countries. To support an economic argument for such intervention, we adduce recent evidence which shows that improving early childhood health raises the future quality of life and, in addition, has multiplier effects, stimulating human capital investment and raising employment and earnings.
\end{abstract}

Keywords: child health, infectious disease, early life origins of socioeconomic inequality, diseasepoverty trap, intergenerational transmission of health, globalization, patents, justice, Health Impact Fund.

Boxes for the book chapter containing "five key messages", "three policy implications" and "key readings" appear at the end of the paper.

\footnotetext{
1 Sonia Bhalotra is Professor of Economics at the University of Bristol and Thomas Pogge is Leitner Professor of Philosophy and International Affairs at Yale University. Contact: s.bhalotra@bristol.ac.uk, thomas.pogge@yale.edu.
} 


\title{
Ethical and Economic Perspectives on Global Health Interventions
}

\author{
Sonia Bhalotra and Thomas Pogge
}

\section{Introduction}

Our approach is conditioned by three factors. First, the global burden of disease is largely borne by poor countries. Second, within poor countries, it is largely borne by children. Third, poverty heightens the risk of contracting disease and childhood exposure to disease causes poverty in later life and, plausibly, into the next generation.

The first factor may suggest that improving global health is essentially the duty of poorcountry governments, but we present ethical and economic arguments against this view. The second and third factors suggest that health interventions may be self-financing and self-sustaining within the span of a generation and, overall, not only intrinsically desirable but also cost-effective. However, commitment problems arise in achieving international coordination of interventions and these are enhanced by the fact that some costs of inaction flow in an intergenerational frame (familiar from debates about climate change). This motivates consideration of global institutional reforms focused on alleviating disease burdens borne by children and especially by girls.

We suggest how contemporary global institutions shaping the development, pricing and distribution of vaccines and drugs may be modified to deliver large improvements in health. We show how interventions that improve childhood health directly improve the quality of life and, in addition, have multiplier effects, producing long-term population and economic gains in poor countries. They also tend to generate positive spillovers for richer countries through reductions in population growth, migration, pollution, and the externalities of infectious disease. To support a justice argument for such modification, we show how the current global economic order may contribute to perpetuating poverty and poor health in developing countries. We argue that millions of poor people are caught in a poverty-disease "trap", the origins of which are typically in their early childhood and, indeed, their parents' childhood. This suggests an explanatory role for past global institutions, in which slavery and colonial rule loom large. ${ }^{2}$

2 Recent research in economics shows persistent impacts of slavery and colonial institutions on a range of contemporary outcomes including inequality, economic growth and polygamy (Sacerdote 2005, Acemoglu et al. 2001, Fenske 2011). 
Recent estimates suggest that the gains in life expectancy in the United States over the $20^{\text {th }}$ century were worth more than $\$ 1.2$ million per person to the current population (Murphy and Topel 2005). If we allow for the intrinsic value of life, for the longer horizon of life for children (as opposed to adults) saved from death, for next generation effects, and for socioeconomic gains from health, then the benefits for poor countries are possibly larger. Moreover, the costs of prevention and cure are likely lower in poor countries where substantial health gains can be achieved by evidence-based interventions such as provision of clean water, micronutrients, oral rehydration therapy, insecticide-treated bed nets, vaccines and generic antibiotics. In general, addressing infectious disease prevalence is much cheaper than addressing chronic disease (e.g., cancer and diabetes) which is prevalent in richer countries and emerging rapidly in poorer countries. This is pertinent given that there is some evidence that preventing infectious disease in childhood lowers the risk of chronic disease in adulthood (Barker and Osmond 1986, Barker 1992).

The gap in life expectancy between rich and poor countries is today about thirty years, and the difference is on account of child mortality. Someone born in Sierra Leone is about 87 times as likely to die in childhood as someone born in Sweden (Deaton 2007). Between 1850 and 1950, most high-income countries experienced historically unprecedented declines in child mortality from the control of infectious disease. This raised life expectancy at birth by nearly thirty years (Cutler et al. 2006). Today less than $1 \%$ of all deaths in richer countries are of children under the age of five, while child deaths still dominate mortality in poorer countries. Some 7.6 million children are dying each year before they turn five (www.unicef.org/media/media_59795.html) and avoidably so (Jones et al. 2003). The knowledge (e.g., concerning sanitation) and innovation (e.g., antibiotics) that were successful in richer countries are now available to poorer countries. Yet, in poorer countries only about $20 \%$ of children have access to safe water and only $20 \%$ of children who need antibiotics to treat pneumonia receive them (WHO 2010).

The costs of adequate nutrition and treatment are too small for poverty alone to explain the persistence of high levels of disease (Deaton 2007). But because poverty is a major contributor to morbidity and mortality, it is pertinent to note that the world poverty problem, which is so large in human terms, is small in economic terms. In 2005, the shortfall of the world's poor from an adequate standard of living amounted to about 2 percent of global household income or 1.2 percent 
of world income. ${ }^{3}$ This global poverty gap could have been filled almost twice over, just from the gain in the share of the richest ventile during 1988-2005 (Section 3 below). The widespread poverty we see today, like widespread ill-health, is largely avoidable.

In this essay we underline the role of a global political economy in generating significant barriers to improvements in both disease and poverty.

The relevance of political factors at the national level is widely recognized. Foreign aid to the developing world is often characterized as being captured or dissipated by corrupt or failed governments (Temple 2010: section 7). What is relatively unrecognized is the bearing of the broader international political economy upon this state of affairs and, further, on the shape of global institutional arrangements as they pertain to disease and poverty. Even where democratic, governments that have signed up to international agreements do not necessarily represent the preferences of their people. For these reasons, we suggest here a reconsideration of the current institutional order, focusing upon aspects that impinge upon health. The preservation of human rights provides an excellent starting point but we underline that this is a domain in which pursuit of this goal is compatible with widespread and lasting human and economic gains.

The essay is structured as follows. Section 2 pulls together new evidence from epidemiology and economics that illustrates relevant causal pathways and demonstrates the costs of failing to intervene. This evidence demonstrates that health inteventions in developing countries tend to directly produce improvements in early-life health and cognitive development and, by raising their productivity, to stimulate further human capital investments. Recent studies show that there are often very large impacts on labour market outcomes. We also underline the significance of investing in the nutrition and health of girls as this appears to be key to breaking the intergenerational persistence of ill health and poverty. Section 3 argues that richer countries have not only the incentives to contribute to disease mitigation in poorer countries but also an active moral responsibility to do so. Section 4 concludes.

\section{Hidden and Long-Term Returns to Disease Mitigation}

This section argues that mitigating infectious disease in poor countries and providing all children with a healthy start will bring about continued gains and convergence in health and socio-

\footnotetext{
3 This accords roughly with the World Bank's PPP-based tally which counted 3,085 million people as living in severe poverty in 2005 and estimated their collective shortfall — the global poverty gap — at 1.13 percent of world income. See Thomas Pogge, Politics as Usual (Cambridge: Polity Press 2010), 69.
} 
economic status across the lifespan of the exposed generation and the next. Much of the literature on inequality of opportunity at birth focuses upon the influence of parental resources and attitudes on investments in children (Black et al., 2007; Cunha and Heckman, 2009). We highlight evidence from new work focusing on the importance of early-life health (Currie, 2009; Almond and Currie, 2011). ${ }^{4}$ The effect sizes in this literature are large enough to suggest that interventions against infectious disease (effectively targeting infant health) may be more effective at raising educational performance and income in poor countries than conventional interventions such as reducing class size (Miguel and Kremer, 2004; Kremer and Holla 2009). Prioritizing the health of girls (widely disadvantaged today) can further enhance these long-term benefits because mothers are pivotal in the intergenerational transmission of health (Bhalotra and Rawlings, 2010). We now develop these arguments in a natural sequence.

\subsection{Infectious Disease: the Importance of Childhood}

The primary proximate cause of death in poor countries is infectious disease. Pneumonia, HIV/AIDS, diarrhea, tuberculosis and malaria exert the largest toll. Under-nutrition lowers resistance to infectious disease which in turn aggravates under-nutrition (Black et al. 2003, Jones et al. 2003). ${ }^{5}$ Young children are especially vulnerable because their immune systems are immature and because the metabolic cost of nutritional deprivation is especially large in the peak years of human growth. Many children die. Others survive, assisted by adaptive physiological changes such as reduced body size or an altered kidney morphology. Recent research suggests that this short-term thrift may exert a penalty in the longer run, making survivors of childhood disease more likely to contract chronic diseases like cancer, cardiovascular problems and diabetes later in life (Barker 1997, Almond and Currie 2011). These adverse effects are thought to be larger when, as in many (growing) developing countries, the nutritional environment changes dramatically over the life course.

\subsection{Chronic Disease}

The "Barker hypothesis" [above] suggests that the emergence of chronic diseases in poor countries may be aggravated by infectious disease exposure fifty to sixty years ago. This is when many of these countries were still under colonial rule or just emerging from it, and many were largely unexposed to the biomedical and technological innovations that reduced infectious disease in richer

\footnotetext{
${ }^{4}$ We provide relevant examples rather than a comprehensive survey of this literature.

5 There are two mechanisms for the latter. First, the immune response generated to fight infection is resource-intensive and taxes available nutritional resources (Crimmins and Finch 2004). Second, infectious disease tends to moderate appetite and to inhibit assimilation of nutrition (Scrimshaw, Taylor and Gordon 1968).
} 
countries in the late $19^{\text {th }}$ and early $20^{\text {th }}$ century. It also suggests that many less-developed countries today carry a double burden of disease: young children continue to suffer morbidity and mortality from infectious disease at an unnecessarily high rate while chronic disease is taking hold in the adult population.

\subsection{Infectious Disease, Cognitive Development and Poverty}

Brain development consumes a very large share of metabolic resources in early life $(85 \%$ compared with $25 \%$ in adults), and resource deprivation therefore endangers cognitive development (Eppig, Fincher and Thornhill 2010, Bharadwaj and Neilson 2011, Bhalotra and Venkataramani 2012a). Moreover, there is evidence suggesting (a) the productivity of investments in an individual's health and education is lower when the endowments that they start out with are weaker, and (b) investments in health and education are mutually reinforcing (Cunha and Heckman, 2007; Glewwe and Miguel, 2008). Related evidence shows that increases in life expectancy stimulate increased investments in education, consistent with the returns to education flowing over a longer horizon. This is nicely illustrated by Jayachandran and Lleras-Muney (2010), showing that a sharp drop in maternal mortality in Sri Lanka stimulated investment in the education of girls.

These dynamic complementarities imply that the damage incurred by poor fetal and infant health may grow larger rather than fade over time, and may scar not only future health but also adult cognitive attainment and, by these processes, adult earnings. In this way, early-life disease causes later life poverty (Currie 2009, Bhalotra and Venkataramani 2012b) which causes children of the next generation to start life in poor health. This causal chain runs across generations in an endogenous process that may be characterized as a poverty trap in which ill health is the primary mechanism (Currie and Moretti 2007, Bhalotra and Rawlings 2010, 2012). By their nature, poverty traps call for external intervention as there is no evident spontaneous mechanism by which they dissipate (Bonds et al. 2010).

There is widespread recognition that poverty leads to ill health (Gwatkin et. al. 2000, Friel and Marmot 2011). It is less widely known that ill health leads to poverty (or that health-promoting interventions produce educational and income gains). ${ }^{6}$ One reason for this is that long-range longitudinal data is scarce and the causal impact of health on income or poverty takes time to emerge (the time from early childhood to employment or child rearing). Another reason is the

\footnotetext{
${ }^{6}$ As discussed earlier, this is relevant insofar as health interventions may eventually pay for themselves, but also insofar as it motivates the participation of richer countries that may stand to benefit from lower disease levels and higher levels of economic growth in developing countries.
} 
difficulty of identifying causality when the relationship runs in both directions and is subject to confounders. Recent studies address this challenge. A twenty-year follow-up of a randomized control trial involving de-worming in Kenyan schools estimates that treatment generated 2-3 additional years of schooling and a 21-29\% increase in income (Baird et al., 2011). Other studies using cohort data on large-scale historical health interventions arrive at remarkably similar estimates. Bleakley (2010) estimates that malaria eradication in the Americas increased wage income by 15$27 \%$, and Bhalotra and Venkataramani (2012b) estimate that the 30\% drop in infant pneumonia mortality after the introduction of antibacterials was associated with a $19 \%$ income gain for survivors exposed to the disease in infancy. ${ }^{7}$

\subsection{Health Inequalities and Institutional Design}

Because infectious diseases are more prevalent amongst the poor, their prevention and cure reduce health and thereby socioeconomic inequalities. However, the design of institutions mediates this process. Here we present some compelling illustrations from recent US history, which are of generic relevance to our central thesis: that the full benefit of other changes (such as rising incomes in developing countries) may depend upon institutional change (or, the lifting of institutional barriers to access and opportunity).

Pneumonia was the leading cause of death in the early 1930s, twice as prevalent among (poorer) African-Americans as among whites. In both populations, infection rates were highest amongst infants. Upon the introduction in 1937 of sulfonamides, the first antibiotics, pneumonia fell sharply in both populations, but the absolute health gain for blacks was larger, in line with their higher pre-intervention exposure levels. Using econometric methods that isolate the impact of reduced pneumonia exposure in infancy on later life outcomes, we find that the education and incomes of whites benefited enormously from being born just after 1937 as compared with just before, but there were, on average, no similar socioeconomic gains for African-Americans. We show that this can be traced to racial segregation in schools and labour markets (in the South in particular) that limited both the opportunities and incentives for blacks to make complementary human capital investments (Bhalotra and Venkataramani, 2012b). The results for whites illustrate how effectively interventions that improve early-life health can produce socio-economic gains by encouraging

\footnotetext{
7 These results, obtained on microdata, reflect partial equilibrium outcomes. Acemoglu and Johnson (2007) present an opposing view using cross-country data. They show that large-scale health interventions in the 1950s did raise GDP but as they also raised the population, there were no significant increases in per capita GDP. These results are contended in Bleakley (2006) and Bloom et al. (2009).
} 
reinforcing investments in health and education while the results for blacks illustrate how this translation may be inhibited by "extractive" institutions that inhibit sections of the population from realizing potential returns.

Some thirty years later, Title VI of the 1964 Civil Rights Act, mandating desegregation in institutions receiving federal funds, provided a further positive shock to health endowments, this time, unique to African-Americans. The integration of hospitals led to a substantial narrowing of the racial gap in post-neonatal infant mortality (Almond and Chay, 2007) and this has been shown to have been a key driver of the improved test performance of black teenagers in the 1980s (Chay, Guryan and Mazumder, 2009).

\subsection{The Intergenerational Transmission of Health}

The previous subsection outlines compelling evidence that childhood health interventions lead not only to immediate reductions in morbidity and mortality amongst children, but also to health and socioeconomic gains in adulthood. These, in turn, stand to raise the health and subsequent socioeconomic status of their children. In this way the benefits of a one-off intervention today persist into the future. There is some direct evidence of intergenerational impacts of early life health interventions. For instance, girls exposed to the Great Chinese Famine grew up to have less healthy children (Fung and Wei 2010), and girls born into conditions of high infant mortality have children less likely to survive infancy (Bhalotra 2010). Immunization programs, as much as economic growth, have been shown to attenuate the intergenerational transmission of health at the low end of the maternal health distribution (Bhalotra and Rawlings 2012) - yet girls are routinely less likely to be immunized in many poor countries (Oster 2009, Bharadwaj and Nelson 2010). Since mother-child transmission of health tends to be stronger than father-child, these results imply that interventions that erase gender disparities in child health are supported by efficiency as well as equity considerations (see references in Bhalotra and Rawlings 2010).

\subsection{Health Interventions and Population Growth}

Health interventions may influence population growth through their impacts on mortality, fertility (Galor and Weil 1996, Galor 2010, Bhalotra and van Soest 2008) and migration (Mesnard and Seabright 2009). Fertility may be expected to respond to the mother's health endowment and to changes in the health and survival prospects of potential offspring. Fertility declined just after the early twentieth century eradication of hookworm in the US South and the large-scale antibiotic treatment of pneumonia, consistent with parents substituting "quality" for "quantity" of children 
(Bleakley and Lange 2009, Bhalotra, Hollywood and Venkataramani 2012). The 1991 clean water reform in Mexico, which sharply reduced morbidity and mortality from diarrhea, also led to a decline in fertility (Bhalotra and Venkataramani 2012a). The tendency for mothers to have fewer births once their (potential) offspring become more likely to thrive suggests a pathway from disease mitigation to lower population growth and more rapid economic growth (Galor and Weil 2000).

In sum, there is evidence of causal links flowing from improvements in early-life health to cognitive development, education and earnings (section 2.3) and some evidence that investments in the early-life health of women are particularly beneficial because they produce returns in the second generation (section 2.5). Drawing upon the evidence regarding fertility (this section), we conclude that investments in child and especially girl health promise lasting health and socio-economic gains, alongside other (social and economic) changes that enable women to make productive contributions beyond childbearing.

\subsection{The Globalization of Disease}

Human alteration of ecosystems in the processes underlying economic growth (e.g., urbanization, irrigation, deforestation) facilitates the emergence and spread of infectious diseases. Diseases evolve in unpredictable ways. The post-World War I global influenza epidemic of 1918-20 killed an estimated 50-100 million people, including half a million in the United States alone. The current "swine flu" or H1N1 virus has evolved from an old form of ("Asian") flu which assimilated elements of avian and swine flu. Older diseases like malaria and tuberculosis are re-emerging on account of microbial resistance to existing drugs. Globalization, or the flow of information, goods, capital and people across political and geographic boundaries, has helped spread some of the deadliest infectious diseases known to humans. In recent history, bubonic plague, influenza, SARS and HIV/AIDS have spread from poor to richer countries. Disease crosses international borders more easily with increases in air travel ${ }^{8}$ (Lederberg 1997), mass migrations due to wars or natural disasters (Montalvo and Reynal-Querol 2007, Blattman and Miguel 2010, BBC 2004) and trade in agricultural products. Globalization has increased not only the spread of infectious diseases from South to North, but also the risk of non-communicable diseases spreading by transmission of cultural behavior from North to South (Brown and Labonte 2011 and Chapter 32 in this volume).

\footnotetext{
8 Air travel enables people to go to foreign lands, contract a disease and not have any symptoms of illness until after they get home, having exposed others along the way. The West Nile Virus is believed to have reached New York City in 1999 via mosquitoes riding in airplane wheel wells.
} 


\section{Health, Justice and Global Institutions}

Building upon the empirical insights outlined in Section 2, this Section argues that richer countries have an active moral responsibility to contribute to mitigating the disease burden in poor countries, based on their ongoing contribution, through design and imposition of the current global institutional order, to the persistence of the poverty-disease cycle in the developing world.

\subsection{Patents and Drug Prices}

As disease is growing increasingly globalized, so is the management of disease. One central component of globalization has been the creation of an increasingly dense and influential supranational system of rules and actors that shape and regulate not only the ever-growing share of interactions that traverse national borders but also purely domestic interactions, profoundly shaping, for instance, trade, investment, innovation, working conditions, environmental protection, and the availability of weapons. In particular, the 1994 TRIPS Agreement, created with the World Trade Organization (WTO), has shifted important rules governing the development and sale of medicines from the national to the global level.

The TRIPS Agreement entitles pharmaceutical firms to protect their innovations with twenty-year product patents, which enable them to suppress generic competition. ${ }^{9}$ This has raised the prices of new medicines in the developing world to many times the marginal cost of production, thereby making many treatments inaccessible to those who need them most. ${ }^{10}$

A common defense of TRIPS is that the manufacture and sale of generic products are moral crimes ("theft", "counterfeiting", "piracy") that any just legal system ought to suppress (Nozick 1974:182). But the defenders of this view have not managed to provide a convincing argument to show why the fact that one person has made a new product should give her a natural right to bar others from making a like product out of their own raw materials (Hollis and Pogge 2008: Chapter

\footnotetext{
9 "TRIPS” stands for Trade-Related Aspects of Intellectual Property Rights. The TRIPS Agreement resulted from strong lobbying by the agribusinesses and pharmaceutical, entertainment and software industries. Product patents allow patentees to veto the manufacture and sale of a patented molecule regardless of how it is produced. Before TRIPS, India granted only process patents, which allow patentees to veto merely a specific way of making a molecule. India is the leading supplier of medicines in the less-developed countries. See WHO 2011 and Chapter 24 below.

10 Parallel-import and reference-pricing problems notwithstanding, pharmaceutical firms often find it profitable to sell their patented products in poorer countries at lower prices. But even intra-national inequalities are nowadays so large that in most less-developed countries an important medicine's domestically profit-maximizing sales price will place it out of reach of the majority of the country's population (Flynn, Hollis and Palmedo 2009).
} 
5). Patents fit poorly with libertarian views which celebrate property rights and freedom since they restrict the freedom to use one's physical property in novel ways.

Another defense states that poor countries signed the TRIPS Agreement voluntarily. But many had little understanding of its implications at the time and they needed the improved access to rich country markets that was then offered in return. The interests of the poor majority were often given little weight in the deliberations of those who held political power in less-developed countries (Chapter 24 below).

In view of the difficulty of formulating convincing appeals to natural law or informed consent, most TRIPS defenders resort to pragmatic arguments stressing the need for economic incentives. The proposition is that potential innovators will develop new medicines only if this can earn them a decent return on their investment (WTO 2012); and such medicines, while immediately benefiting only the rich, will eventually go generic and then benefit poor patients as well. A weakness of this argument is that, by the time a medicine goes generic, its effectiveness may have been eroded by microbial adaptation or other changes. Another, neglected drawback is the long-term cost of the delay arising from the intergenerational effects of poor childhood health (Section 2).

Despite these problems, the status quo might be defensible if the development of important new medicines could be stimulated only through patent-protected mark-ups that exclude poor patients during the patent period. However recent evidence suggests that the extension of strong patent protections into developing countries has not stimulated $R \& D$ investment in the diseases prevalent there (Kyle and McGahan 2012). But various plausible alternative mechanisms, designed to overcome existing access problems, have been proposed over the last decade. ${ }^{11}$ Here we discuss one such mechanism, the Health Impact Fund (HIF), which would complement the existing system by offering innovators the option to register a new medicine or, under certain conditions, a traditional medicine or a new use of an existing medicine. By registering a product, the innovator would undertake to make it available globally, during its first ten years on the market, at no more than the lowest feasible cost of production and distribution. The innovator would further commit to allowing, at no charge, generic production and distribution of the product after this decade has ended. In exchange, the registrant would during this decade receive annual reward payments based

\footnotetext{
${ }^{11}$ Most of the more plausible proposals are described and discussed in the work of the WHO Consultative Expert Working Group on Research and Development (CEWG), available at www.who.int/phi/news/cewg_2011/en/index.html.
} 
on its product's health impact. ${ }^{12}$ Each reward payment would be part of a large constant annual payout, with every registered product receiving a share equal to its share of the assessed health impact of all HIF-registered products in the relevant year.

The HIF is potentially beneficial on three fronts. First, it would foster development of important medicines against diseases concentrated among the poor. Pharmaceutical innovators are now neglecting such diseases because they have no realistic hope of recovering their R\&D costs from sales to the poor (Moran et al. 2009). Second, the HIF would at any time support availability of a set of vital new medicines worldwide at very low prices. Third, the HIF would motivate registrants to ensure that their products are widely available, perhaps even below the price ceiling, and that they are competently prescribed and optimally used. ${ }^{13}$ Registrants would be rewarded not for merely selling their products, but for making them effective toward improving global health.

The HIF's annual reward pools might initially be set at $\$ 6$ billion - about 0.03 percent of the gross national products of China plus the US or Brazil plus the EU. If HIF-rewarded innovations were funded through taxes, affluent people would bear most of the cost and poor people would contribute little or nothing — just like under the current system. The key difference is that, instead of being excluded by large mark-ups, poor patients would gain access to HIF-rewarded medicines at prices that cover the cost of manufacture and distribution. By funding pharmaceutical innovation in this new way, affluent populations stand to benefit from lower drug prices (directly and through lower expenses for insurance, national health systems, and foreign aid), from better marketing of drugs for optimal health impact, from faster economic growth in poorer countries and from reduced transmission of infectious diseases to richer countries (Section 2).

By funding the HIF, affluent populations would also reduce their role in a grievous injustice. The HIF model shows clearly that the development of new medicines can be incentivized in a way that allows poor patients immediate access at the cost of manufacture and distribution. In view of this possibility, it is wrong for the affluent to choose to incentivize the development of important new medicines for themselves through the worldwide enforcement of temporary monopolies that prevent generic manufacturers from supplying cheap copies to poor patients.

\footnotetext{
12 Measured in quality-adjusted life years saved. The QALY metric has been refined over the last 20 years and is already widely used, e.g., by public and private insurers deciding which new drugs to cover (Phillips 2009).

13 A registrant would want to offer its product below cost if and insofar as it expects its additional health impact rewards due to reaching additional patients to be larger than its loss on the sales price. A registrant would want to promote the wide and proper use of its product, especially by those who can benefit most from it, if and insofar as the additional health impact rewards due to such efforts exceed their costs.
} 


\subsection{Global Institutions and Social Justice}

We first show that there are vast income inequalities across the world. We then illustrate how supranational institutional arrangements may be aggravating inequality and poverty worldwide (Pogge 2004). The final subsection sets out the tenets of a case for global health interventions from the standpoint of moral and political philosophy.

\subsubsection{Poverty and inequality at birth}

Some defenders of TRIPS contend that it is natural and not unfair that affluent people have all kinds of expensive things that poor people cannot afford to buy. This contention assumes an acceptable distribution of income and wealth. But are existing economic inequalities fair? They have accumulated over a history of colonial conquest, enslavement, exploitation and genocide. Over $80 \%$ of income variability worldwide is explained by a person's country and socio-economic class at birth (Milanovic 2009).

\begin{tabular}{|c|c|c|c|c|}
$\begin{array}{c}\text { Segment } \\
\text { of World } \\
\text { Population }\end{array}$ & $\begin{array}{c}\text { Share of } \\
\text { Global } \\
\text { Household } \\
\text { Income } \\
1988\end{array}$ & $\begin{array}{c}\text { Share of } \\
\text { Global } \\
\text { Household } \\
\text { Income } \\
2005\end{array}$ & $\begin{array}{c}\text { Absolute } \\
\text { Change in } \\
\text { Income } \\
\text { Share }\end{array}$ & $\begin{array}{c}\text { Relative } \\
\text { Change in } \\
\text { Income } \\
\text { Share }\end{array}$ \\
\hline $\begin{array}{c}\text { Richest 5 } \\
\text { Percent }\end{array}$ & 42.87 & 46.36 & +3.49 & $+8.1 \%$ \\
\hline $\begin{array}{c}\text { Next 5 } \\
\text { Percent }\end{array}$ & 21.80 & 22.18 & +0.38 & $+1.7 \%$ \\
\hline $\begin{array}{c}\text { Next 15 } \\
\text { Percent }\end{array}$ & 24.83 & 21.80 & -3.03 & $-12.2 \%$ \\
\hline $\begin{array}{c}\text { Second } \\
\text { Quarter }\end{array}$ & 6.97 & 6.74 & -0.23 & $-3.3 \%$ \\
\hline $\begin{array}{c}\text { Third } \\
\text { Quarter }\end{array}$ & 2.37 & 2.14 & -0.23 & $-9.7 \%$ \\
\hline $\begin{array}{c}\text { Poorest } \\
\text { Quarter }\end{array}$ & 1.16 & 0.78 & -0.38 & $-32.8 \%$ \\
\hline
\end{tabular}

Table 1: The Evolution of Global Income Inequality

As Table 1 shows, the richest ventile $(5 \%)$ of the global income distribution has gained substantially over the globalization period, while the poorest $90 \%$ have lost ground. ${ }^{14}$ With the losses most severe in the poorest quarter, income has become more polarized: across seventeen years, the ratio between the average income in the richest ventile and that in the poorest quarter has

\footnotetext{
14 The data used in this table were kindly supplied by Branko Milanovic, lead economist in the World Bank's Research Department, in a personal e-mail communication on April 25, 2010 (on file with authors). Milanovic is a leading authority on the measurement of socio-economic inequality.
} 
skyrocketed from 185 to 297 . By 2005 , the poorer two-thirds of humanity had merely $6 \%$ of global household income and 3.34\% of global private wealth (Keating et al. 2011, p.14).

\subsubsection{Global factors in the perpetuation of poverty and inequality}

A familiar argument against foreign aid or other international interventions is that they do not reach the target population on account of developing-country governments being corrupt (e.g., Temple 2011). But corruption is often encouraged by the economic interests of richer nations. For instance, affluent countries and their banks may lend money to corrupt rulers and compel the country's people to repay it after the ruler is gone. Many poor populations are still repaying debts incurred, against their will, by kleptocrats such as Suharto in Indonesia, Mobutu in the Democratic Republic of the Congo, Abacha in Nigeria and Mubarak in Egypt. Second, affluent countries facilitate the embezzlement of funds by public officials in less developed countries by allowing their banks to accept such funds. This complicity could easily be avoided: banks are already under strict reporting requirements with regard to funds suspected of being related to terrorism or drug trafficking. Yet Western banks still eagerly accept and manage embezzled funds, with governments ensuring that their banks remain attractive for such illicit deposits. Global Financial Integrity (GFI) estimates that less-developed countries have in this way lost $\$ 357-417$ billion annually during the 2000-2008 period. ${ }^{15}$ Third, affluent countries may facilitate tax evasion in less-developed countries through lax accounting standards for multinational corporations. Since they are not required to do country-by-country reporting, such corporations can easily manipulate transfer prices among their subsidiaries to concentrate their profits where these are taxed the least. As a result, they may report no profit in the countries in which they extract, manufacture or sell goods or services, having their worldwide profits taxed instead in a tax haven where they only have a paper presence. GFI estimates that, during the 2000-2008 time period, trade mispricing deprived developing countries of \$366-427 billion per annum. ${ }^{16}$ Fourth, affluent countries and their firms often buy natural resources from the rulers of less-developed countries without regard for how such rulers came to or exercise power. In many cases, this amounts to collaboration in the theft of these resources from their owners, the country's people. It also enriches their oppressors, thereby entrenching the oppression: tyrants sell

\footnotetext{
${ }^{15} \mathrm{Kar}$ and Curcio 2011, pp. 3, 21, 37. This outflow is over four times larger than all official development assistance which, during this period, averaged $\$ 83.7$ billion annually, of which only $\$ 8.1$ billion was allocated to "basic social services." United Nations, MDG Indicators, http://unstats.un.org/unsd/mdg/Search.aspx?q=bss\%20oda.

${ }^{16}$ Ibid., p. 37. This is the other 50.6 percent of illicit financial outflows.
} 
their victims' natural resources and use the proceeds to buy the weapons they need to keep themselves in power (Pogge 2008, Wenar 2008).

Affluent countries also contribute to the problem by altering the environmental, political and economic landscape. They account for a disproportionate share of global pollution. Their emissions are prime contributors to serious health hazards, extreme weather events, rising sea levels, food and water insecurity and climate change, to which poor populations are especially vulnerable. A recent report by the Global Humanitarian Forum estimates that climate change is already seriously affecting 325 million people and annually causing \$125 billion in economic losses plus 300,000 deaths, of which 99\% are in less-developed countries (GHF 2009: pp. 1, 60-61). Richer countries encouraged conflict within Africa during the Cold War (Dunning 2004). War has persistent impacts on health, human capital and hence long-term growth in poor countries (Blattman and Miguel 2010, Akresh et al. 2011). Richer countries have created a global trading regime that is cast as generating large collective gains through free and open markets. But the regime is rigged; it permits rich states to continue to protect their markets through tariffs and anti-dumping duties and to gain larger world market shares through export credits and subsidies (including some $\$ 227$ billion annually in agriculture alone) which poor countries cannot afford to match. ${ }^{17}$ Because production is much more labor-intensive in poor than in affluent countries, such protectionist measures tend to destroy many more jobs in poor than they create in more affluent countries.

\subsubsection{The justice case}

The core function of institutional arrangements - of the rules and practices structuring a national society or other social system - is to protect the freedom and well-being of the individuals whose lives are governed or profoundly affected by them. Physical and mental health is fundamental to both freedom and well-being. Institutional arrangements ought then to be designed and (if needed) reformed so as to enable those whose lives they profoundly affect to lead full and healthy lives.

This widely accepted thought is often connected with the value of solidarity (or risk-sharing). All human beings are vulnerable to various serious threats to their physical and mental health, and we can cope much better with these threats when we pool some of our resources. To be sure, participation in a scheme of organized solidarity will not be equally advantageous for all, even ex ante. Some will not be able to contribute a lot to the pool and some will foreseeably place greater burdens

17 OECD 2011, p. 18, also stating that in 2010 government subsidies accounted for 18 percent of gross farm receipts in OECD countries. 
on it; and such people are then likely to receive a share of the scheme's benefits that is larger than their share in the scheme's cost. But solidarity is a strong moral reason to include and to assist the more vulnerable among us.

While we endorse this call for solidarity, both within and beyond national borders, we also recognize that, on its own, it conveys an incomplete and potentially misleading picture. Institutional arrangements not merely address some of the health problems and vulnerabilities that individuals bring with them into society. They also shape these people and their environments, thereby profoundly affecting what health problems and vulnerabilities people face in the first place. Social institutions influence access to nutrients and patterns of environmental hazards, for example, and the resulting childhood exposure to malnutrition or lead pollution can have serious effects on persons' health needs for the rest of their lives (Section 2). Similarly consequential for health are a society's choices about public hygiene and sanitation, access to health knowledge, traffic rules, law enforcement, political competition and protections against domestic and employer abuse. Persons whose health has been undermined by avoidable defects in any of these social factors can plead for solidarity, of course. But they can also invoke the more stringent value of justice.

One might say in response that, just like health care, the social determinants of health fall exclusively under the value of solidarity, which is lacking in a social order under which people are avoidably left to starve or must find their own way of protecting themselves from assault. We hold that such a social order is also unjust. Those upholding it are not merely insufficiently attentive to the needs of some of those on whom they impose it, but can also be said to be actively harming them. To be sure, one is not harming unemployed persons when one fails to provide them with food they need to survive. But one is harming when one imposes institutional arrangements under which foreseeably some are avoidably unable to meet their basic needs.

Because human rights are constraints on government conduct, including that of upholding national and international institutional arrangements, governments may not be the most reliable judges of what human rights there are. Their documents nonetheless deserve attention. The two most prominent references to health in these documents affirm that "Everyone has the right to a standard of living adequate for the health of himself and of his family, including food, clothing, housing and medical care and necessary social services" (Universal Declaration of Human Rights, Article 25.1) as well as "the right of everyone to the enjoyment of the highest attainable standard of physical and mental health" (International Covenant on Economic, Social and Cultural Rights, Article 12.1). 
The latter formulation may need some explication. As the word "standard" indicates, it is not here postulated that each person has a claim to whatever resources may be needed to maintain her in, or restore her to, good health. The assertion is rather that each is entitled to enjoy whatever plausible overall standard can reasonably be achieved for all. Here three limiting considerations come into play. First, for some specific piece of health protection (a safe water supply, say, or some medical procedure) to count as "attainable," it must be achievable for all and not merely for some. Second, for a specific piece of health protection to count as achievable for all, it must be achievable not merely by itself, but as part of a plausible package of health protections that can be simultaneously achieved for all. This is why we speak of a plausible overall standard, one that covers a set of diverse health protections intelligently selected in light of a society's capacities and all relevant costs, opportunity costs, synergies, complementarities, etc. Third, there should be no requirement to assign absolute priority to health over everything else (such as culture, education, and leisure time). Even if a higher standard of health could be attained by eradicating all wild animals, for example, a society may judge this cost to be unreasonably high relative to the health gains attainable through it.

Some still claim supranational arrangements (such as TRIPS) as a morality-free zone in which the concept of justice has no application (Nagel 2005). But, on reflection, this claim is hard to justify. ${ }^{18}$ If it is unjust for each of a group of governments to impose certain rules upon its own country's population, then it must also be unjust for this same group of governments to impose the same rules upon all their countries' populations pursuant to some international agreement.

The upholding of any institutional order involves a substantial element of coercion, which is morally justifiable only if the institutional order imposed meets certain requirements of social justice. What these requirements are is controversial, especially in the case of supranational institutional arrangements that govern people committed to a wide diversity of moral conceptions. But it is fairly uncontroversial that institutional arrangements must at least be human-rights compliant, that is, must not foreseeably give rise to substantial and reasonably avoidable human rights deficits. ${ }^{19}$

Insisting on this minimal condition is especially important in regard to supranational rules which are not formulated through the kind of transparent, democratic procedures that characterize national law-making in the countries that have reached a basic level of domestic justice. Rather,

\footnotetext{
${ }^{18}$ For further compelling critique of Nagel's view, see Cohen and Sabel 2006.

19 The word "reasonably" is meant to acknowledge not merely the limits of human foresight but also the possibility that the institutional reduction of human rights deficits may sometimes have high costs in terms of culture, say, or the natural environment. It is best to avoid the claim that human rights must never give way in such cases - certainly in modern times, when human rights can be largely or fully realized through institutional reforms that would not entail such high costs.
} 
supranational rules mostly emerge through intergovernmental negotiations that effectively exclude the general public and even the majority of weaker governments. Only a small number of "players" can exert real influence: powerful organizations, prominently including large multinational corporations and banks, very rich individuals and ruling "elites" of the most powerful developing countries. They can reap huge gains from favorable supranational rules and can therefore afford to make large investments into acquiring the necessary expertise, forming alliances and lobbying the stronger (G20) governments that dominate supranational rule-making. Ordinary citizens, by contrast, typically find it prohibitively expensive to acquire the necessary expertise and to form alliances that are large enough to rival corporate influence. In the absence of global democratic institutions, the shift toward global governance sidelines the vast majority of human beings, while greatly enhancing the rule-shaping powers of a tiny minority of those who are already the richest and most powerful. Their interests are diverse, and some elite players fail in their efforts to shape in their favor the rules that stand to impact them the most. Yet, the rules do get captured by some elite players and, as a group, they consequently grow their share of global wealth and expand their advantage over the rest of humankind. This, in turn, further increases their capacity to influence the design and application of the rules in their own favor and, unintentionally but no less inexorably, contributes to keeping the poorer section of humankind in dire poverty.

\section{Conclusions}

In poor countries infectious diseases cause high levels of morbidity and mortality that are avoidable at low cost. While recognizing local barriers to progress on the demand and supply side, we have underlined the role of internationally imposed constraints on progress. We have indicated that interventions targeted at early-childhood health may be among the best investments in poor countries - they are less easily misappropriated than cash transfers, directly improve quality of life, generate positive education and income externalities, are likely to be cost-effective and have built-in tendencies towards being self-sustaining. These factors strengthen the political case for intervening now. Against this backdrop, we have discussed ethical and pragmatic reasons for richer countries to undertake internationally coordinated commitments to tackle disease in poorer countries, focusing attention upon reforming the way pharmaceutical innovation is rewarded.

The present TRIPS system reflects the prejudice that innovation must be rewarded through large mark-ups, at the expense of access by the poor who, if they survive, gain access after patent expiration. We have made the following essential arguments against this regime. First, by an eclectic 
set of widely recognized ethical principles, including libertarian ones at one extreme, the current regime is unfair. Second, it is also unnecessary insofar as there is an alternative feasible regime that would incentivize pharmaceutical R\&D without aggravating health (and thereby economic) inequalities. Third, we have highlighted evidence from epidemiology and economics suggesting that investment in disease mitigation among the poor today is economically wise and, with a lag, likely to pay for itself. Moreover, richer countries and richer people in poor countries have an incentive to contribute to making this investment because improving the health of the poor generates positive externalities for the rich.

A common depiction of the problems of ill health and poverty in poor countries is that they are complex and insurmountable. Furthermore, health problems are often shown to be demanddriven, for example, people may not have relevant information or sufficient education to process new information, leading to low uptake of publicly provided health goods (e.g., Banerjee et al. 2010). While this is valid, the existence of one sort of barrier does not justify imposing another barrier to progress. Economists have documented the relevance of market, government and political failures in contributing to incentive problems and other obstacles in the delivery of public health. We add that there is failure of the international political economy of global health marked by information constraints, commitment problems, poor representation of constituent preferences and limited accountability.

\section{References}

Acemoglu, D., S. Johnson and J. Robinson. 2001. "The Colonial Origins of Comparative Development: An Empirical Investigation.” American Economic Review, Volume 91 (5): 1369-1401.

Acemoglu D, Johnson S. Disease and Development: The Effect of Life Expectancy on Economic Growth. December 2007. Journal of Political Economy 115, pp. 925-985.

Akresh, R., S. Bhalotra, M. Leone and U. Osili. "War and Stature: Growing up during the Nigerian Civil War.” American Economic Review Papers \& Proceedings (forthcoming May 2012). (IZA Discussion Paper 6194, Dec 2011.)

Almond, D. and K. Chay. 2007. The Long-Run and Intergenerational Impact of Poor Infant Health: Evidence from Cohorts Born during the Civil Rights Era. Mimeograph., Columbia University.

Almond, D. and J. Currie. 2011a. "Human Capital Development Before Age Five." In Handbook of Labor Economics, Volume 4b, edited by O. Ashenfelter and D. Card. Elsevier, Volume 4 (5): 1315-1486.

Almond, D. and J. Currie. 2011b. "Killing Me Softly: The Fetal Origins Hypothesis." The Journal of Economic Perspectives, Volume 25 (3): 153-172. 
Baird, S., J. H. Hicks, M. Kremer and E. Miguel. 2011. "Worms and Work: Long-Run Impacts of Child Health Gains.” Mimeograph., University of California, Berkeley.

Banerjee, A. L., Duflo, E., Glennerster, R., and Kothari, D. 2010. "Improving Immunization Coverage in Rural India: A Clustered Randomized Controlled Evaluation of Immunization Campaigns With and Without Incentives." British Medical Journal, 340: c2220. DOI: 10.1136/bmj.c2220.

Barker, D. and C. Osmond. 1986. Infant mortality, childhood nutrition, and ischaemic heart disease in England and Wales. The Lancet, 10 May, v. 1(8489) p. 1077-1081.

Barker, D. 1992. Fetal and Infant Origins of Adult Disease. London: British Medical Journal Publishing Group.

BBC. 2004. "Natural disasters 'on the rise."' September 17. http://news.bbc.co.uk/2/hi/3666474.stm.

Bhalotra, S. and A. Van Soest. 2008. "Birth-Spacing, Fertility and Neonatal Mortality in India: Dynamics, Frailty and Fecundity." Journal of Econometrics, Volume 143 (2): 274-290.

Bhalotra, S. and S. Rawlings. 2010. "Intergenenerational Persistence in Health in Developing Countries: the Penalty of Gender Inequality?” Journal of Public Economics, Volume 95 (3-4): 286-299.

Bhalotra, S. 2010. The Intergenerational Spillover of Early Life Conditions. Mimeograph., University of Bristol.

Bhalotra, S. and S. Rawlings. 2012. "Gradients of the Intergenenerational Transmission of Health in Developing Countries." Review of Economics and Statistics (Online print version available, journal version forthcoming).

Bhalotra, S., and A. Venkataramani. 2012a. Waterborne Disease and Cognitive Development: Quasi-Experimental Evidence From Mexico's 1991 Clean Water Policy. Mimeograph., University of Bristol.

Bhalotra, S. and A. Venkataramani. 2012b. "Shadows of the Captain of the Men of Death: Early Life Health, Human Capital Investment and Institutions. Mimeograph at www.efm.bris.ac.uk/ecsrb/bhalotra.htm

Bhalotra, S., D. Hollywood and A. Venkataramani. 2012. The Fertility Response to Simultaneous Declines in Child and Maternal Mortality: Evidence from the Sulfa Drug Era. Mimeograph., University of Bristol.

Bharadwaj, P. and Christopher Neilson. 2011. The Role of Early Childhood Health Interventions on Mortality and Academic Achievement. Mimeograph., UCSD.

Bharadwaj, P. and Leah Nelson. 2010. Discrimination Begins in the Womb: Evidence of Sex Selective Prenatal Care. Mimeograph., UCSD.

Black, R.E., S. Cousens, H. L. Johnson, J. E. Lawn, I. Rudan, D. G. Bassani, P. Jha, H. Campbell, C. Fischer Walker, R. Cibulskis, T. Eisele, L. Liu and C. Mathers. 2010. "Global, Regional, and National Causes of Child Mortality in 2008: A Systematic Analysis.” The Lancet, Volume 375: 1969-1987.

Black, S.E., P. J. Devereux and K. G. Salvanes. 2007. "From the Cradle to the Labor Market? The Effect of Birth Weight on Adult Outcomes." Quarterly Journal of Economics, Volume 122 (1): 409-439.

Blattman, C. and E. Miguel. 2010. "Civil War." The Journal of Economic Literature, Volume 48 (1): 3-57. DOI: 10.1257/jel.48.1.3. 
Bleakley, H. 2006 "Disease and Development: Comments on Acemoglu and Johnson." Mimeograph, University of Chicago, available at http://home.uchicago.edu/ bleakley/.

Bleakley, H. 2007 "Disease and Development: Evidence from Hookworm Eradication in the American South.” The Quarterly Journal of Economics, Volume 122 (1): 73-117.

Bleakley, H. 2010. "Malaria Eradication in the Americas: A Retrospective Analysis of Childhood Exposure." American Economic Journal: Applied Economics, Volume 2: 1-45.

Bleakley, Hoyt and Fabian Lange. 2009. "Chronic Disease Burden and the Interaction of Education, Fertility, and Growth." Review of Economics and Statistics, Volume 91 (1): 52-65.

Bloom. D., D, Canning and G. Fink. 2009. "Disease and Development Revisited". NBER Working Paper 15137, July.

Bonds, M.H., D.C. Keenan, P. Rohani, and J. D. Sachs. 2010. "Poverty Trap Formed by the Ecology of Infectious Diseases." Proceedings of the Royal Society of London, Series B, Volume 277: 1185-1192. DOI: $10.1098 / \mathrm{rspb} .2009 .1778$

Brown, G.W. and R. Labonte. 2011. "Globalization and its Methodological Discontents: Contextualizing Globalization through the Study of HIV/AIDS." Globalization and Health, Volume 7, (29): 1-12.

Card, David and Alan Krueger. 1992. "School Quality and Black-White Relative Earnings: A Direct Assessment.” The Quarterly Journal of Economics, Vol. 107, No. 1. Feb.: 151-200

Chay, Kenneth, Jonathan Guryan and Bhashkar Mazumder. 2009. "Birth Cohort and the Black-White Achievement Gap: The Role of Access and Health Soon After Birth.” Federal Reserve Bank of Chicago Working Paper 2008-20.

Cohen, Joshua and Charles Sabel. 2006. "Extra Rempublicam Nulla Justitia?" Philosophy and Public Affairs, Volume 34: 147-75.

Crimmins, E.M. and C. E. Finch. 2004. "Inflammatory Exposure and Historical in Human Life-Spans." Science, Volume 305 (5691): 1736-1739.

Cunha, F. and J. Heckman. 2007. "The Technology of Skill Formation.” American Economic Review, Volume 97 (2): 31-47.

Cunha, F. and J. J. Heckman. 2009. "The Economics and Psychology of Inequality and Human Development." Journal of the European Economic Association, Volume 7(2): 320-364.

Currie, J. 2009. "Healthy, Wealthy, and Wise: Socioeconomic Status, Poor Health in Childhood, and Human Capital Development." Journal of Economic Literature, Volume 47: 87-122.

Currie, J. and E. Moretti. 2007. "Biology as Destiny? Short- and Long-Run Determinants of Intergenerational Transmission of Birth Weight." Journal of Labor Economics, Volume 25 (2): 231-264.

Currie, J. and D. Thomas. 2001. "Early Test Scores, Socioeconomic Status, School Quality and Future Outcomes." Research in Labor Economics, Volume 20: 103-132. 
Cutler, D., A. Deaton and A. Lleras-Muney. 2006. "The Determinants of Mortality." Journal of Economic Perspectives, Volume 20 (3): 97-120.

Deaton, A. 2007. "Global Patterns of Income and Health: Facts, Interpretations, and Policies." WIDER Annual Lecture, Helsinki, September.

Dunning, Thad. 2004. "Conditioning the Effects of Aid: Cold War Politics, Donor Credibility and Democracy in Africa." International Organization, Volume 58: 409-423.

Eppig, C., C. L. Fincher and R. Thornhill. 2010. "Parasite Prevalence and the Worldwide Distribution of Cognitive Ability.” Proceedings of the Royal Society, Series B, Volume 277 (1701): 3801-3808.

Fenske, J. 2011. African Polygamy: Past and Present. Mimeograph., University of Oxford.

Flynn, S., A. Hollis and M. Palmedo 2009. "An Economic Justification for Open Access to Essential Medicine Patents in Developing Countries." Journal of Law, Medicine and Ethics, Volume 37(2): 184-208.

Friel, S. and M. G. Marmot 2011. "Action on the Social Determinants of Health and Health Inequities Goes Global.” Anпu Rev Public Health, Volume 32: 225-236. DOI: 10.1146/annurev-publhealth-031210-101220.

Fung, W. and W. Ha. 2010. "Intergenerational Effects of the 1959-61 China Famine." In Risks, Shocks, and Human Development: On the Brink, edited by Fuentes-Nieva and Seck, 222-254. London: Palgrave Macmillan.

Galor, Oded. 2010. "The Demographic Transition: Causes and Consequences." Cliometrica, (forthcoming).

Galor, Oded and David Weil. 1996. "The Gender Gap, Fertility, and Growth." American Economic Review, Volume 86 (3): 374-387.

Galor, Oded and David Weil. 2000. "Population, Technology, and Growth: From Malthusian Stagnation to the Demographic Transition and Beyond." American Economic Review, Volume 90 (4): 806-828.

GHF (Global Humanitarian Forum). 2009. The Anatomy of a Silent Crisis. Geneva: Global Humanitarian Forum.

Glewwe, P. and E. Miguel. 2008. "The Impact of Child Health and Nutrition on Education in Less Developed Countries." In Handbook of Development Economics, edited by J. Strauss and T. Schultz, T. Elsevier, Volume 4 (5): 3561-3606.

Gwatkin, Davidson R., Kiersten Johnson, Rohini P. Pande, Shea Rutstein, and Adam Wagstaff. 2000. "India: Socioeconomic Differences in Health, Nutrition, and Population." Washington, DC. The World Bank, Working Paper 30544. Accessed January 14, 2012. www-wds.worldbank.org/external/default/ WDSContentServer/WDSP/IB/2004/12/06/000012009_20041206145841/Rendered/PDF/305440PAPER 0india.pdf

Hollis, Aidan and Thomas Pogge. 2008. The Health Impact Fund: Making New Medicines Available for All. Incentives for Global Health: Oslo and New Haven. www.yale.edu/macmillan/igh/hif.html.

Jayachandran, S. and A. Lleras-Muney. 2009. "Life Expectancy and Human Capital Investments: Evidence from Maternal Mortality Declines." The Quarterly Journal of Economics, Volume 124 (1): 349-397.

Jones, R. et al. 2003. "How many child deaths can we prevent this year?” The Lancet, Volume 362, (5): 65-71. 
Kar, Dev and Karly Curcio. 2011. Illicit Financial Flows from Developing Countries: 2000-2009. Washington: Global Financial Integrity.

Keating, G., O’Sullivan, M., Shorrocks, A., Davies, J.B., Lluberas, R., and Koutsoukis, A. (2011) Global Wealth Report 2011, Credit Suisse Research Institute, Zurich [https://infocus.creditsuisse.com/data/_product_documents/_shop/323525/2011_global_wealth_report.pdf, accessed July 1, 2012].

Kremer, Michael and Alaka Holla. 2009. "Pricing and Access: Lessons from Randomized Evaluations in Education and Health", in What Works in Development: Thinking Big and Thinking Small, eds. William Easterly and Jessica Cohen. Washington DC: Brookings Institution Press.

Kyle, Margaret K. and Anita M. McGahan. 2012. "Investments in Pharmaceuticals Before and After TRIPS" The Review of Economics and Statistics, prep-publication available at www.mitpressjournals.org/doi/abs/10.1162/REST_a_00214.

Miguel, Edward and Michael Kremer (2004). "Worms: Identifying Impacts on Education and Health in the Presence of Treatment Externalities.” Econometrica, 72(1), 159-217.

Lederberg, J. 1997. Lecture at the College of Physicians of Philadelphia, April 1.

Mesnard, A. and P. Seabright. 2009. "Escaping Infectious Diseases through Migration? Quarantine Measures Under Asymmetric Information about Infection Risk.” Journal of Public Economics, Volume 93: 931-938.

Milanovic, Branko. "Global Inequality of Opportunity: How much of our income is determined at birth?," Cornell University Poverty, Inequality and Development Papers, 2009, at www.arts.cornell.edu/poverty/kanbur/InequalityPapers/Milanovic.pdf.

Montalvo, J. G. and M. Reynal-Querol. 2007. "Fighting Against Malaria: Prevent Wars While Waiting for the Miraculous Vaccines." Review of Economics and Statistics, Volume 89 (1): 165-177.

Moran M., J. Guzman, A-L. Ropars, A. McDonald, N. Jameson, et al. 2009. "Neglected Disease Research and Development: How Much are We Really Spending?" PLoS Medicine, Volume 6 (2), $137-146$. www.plosmedicine.org/article/info:doi/10.1371/journal.pmed.1000030.

Murphy, Kevin M. and Robert H. Topel. 2006. "The Value of Health and Longevity." Journal of Political Economy, Volume 114 (4): 871-904.

Nagel, Thomas. 2005. "The Problem of Global Justice.” Philosophy and Public Affairs, Volume 33: $113-147$.

Nozick, Robert. 1974. Anarchy, State, and Utopia. New York: Basic Books.

OECD (Organization for Economic Cooperation and Development). 2011. Agricultural Policy Monitoring and Evaluation 2011: OECD Countries and Emerging Economies. Paris: OECD.

Oster, E. "Does Increased Access Increase Equality? Gender and Child Health Investments in India." Journal of Development Economics, Volume 89 (1): 62-76.

Phillips, C. 2009. "What is a QALY?"

www.medicine.ox.ac.uk/bandolier/painres/download/whatis/QALY.pdf. 
Pogge, Thomas. 2004. "Relational Conceptions of Justice: Responsibilities for Health Outcomes." In Public Health, Ethics, and Equity, edited by Sudhir Anand, Fabienne Peter, and Amartya Sen, 135-161. Oxford: Clarendon Press.

Pogge, Thomas. 2008. World Poverty and Human Rights: Cosmopolitian Responsibilities and Reforms. $2^{\text {nd }}$ ed. Cambridge: Polity Press.

Sacerdote, B. 2005. "Slavery and the Intergenerational Transmission of Human Capital. Review of Economics and Statistics, Volume 87 (2): 317-234.

Scrimshaw, N., Taylor, C. and Gordon, J. 1968. "Interactions of Nutrition and Infection". Geneva; WHO, 1968, 329 p. Ilus, tablas (OMS Monograph Series, 57).

http://whqlibdoc.who.int/monograph/WHO_MONO_57_\%28part1\%29.pdf

Temple, Jonathan. 2010. “Aid and Conditionality.” In Handbook of Development Economics, edited by Dani Rodrik and Mark R. Rosenzweig, 4415-4523. Elsevier, Volume 5: 4415-4523.

Wenar, Leif. 2008. "Property Rights and the Resource Curse." Philosophy and Public Affairs, Volume 36: 2-32.

World Health Organization (WHO). 2010. "Pneumonia, Factsheet No. 331." Accessed January 14, 2012.

http://www.who.int/mediacentre/factsheets/fs331/en/index.html

World Health Organization (WHO). 2011. "WTO and the TRIPS Agreement." Accessed January 14, 2012. www.who.int/medicines/areas/policy/wto_trips/en/index.html.

World Trade Organization (WTO). 2012. "Intellectual Property: Protection and Enforcement." Accessed January 14, 2012. www.wto.org/english/thewto_e/whatis_e/tif_e/agrm7_e.htm. 


\section{Five key messages}

1. Disease in childhood causes poverty in adulthood and this, in turn, causes children of the next generation to start life in poor health. This causal chain runs across generations to create a poverty trap in which ill health is the primary mechanism. By their nature, poverty traps call for external intervention; there is no evident spontaneous mechanism by which they dissipate.

2. Interventions that improve foetal or infant health tend to raise the productivity of subsequent investments in both health and education. In this way, health begets health, as well as education and earnings.

3. Economists have documented the relevance of market, government and political failures in contributing to incentive problems and other obstacles in the delivery of public health. We add that there is failure of the international political economy of global health marked by information constraints, commitment problems, poor representation of constituent preferences and limited accountability.

4. As disease is growing increasingly globalized, so is the management of disease. Contemporary global institutions shaping the development, pricing and distribution of vaccines and drugs have raised the prices of new medicines in the developing world, making many treatments inaccessible to those who need them most. This is unnecessary, and modified arrangements can deliver large improvements in health.

5. Richer countries have a moral responsibility to contribute to mitigating the disease burden in poor countries based on their contribution, through global institutional design, to the persistence of the poverty-disease cycle in the developing world.

\section{Three key policy implications}

1. Interventions targeted at early-childhood health may be among the best investments in poor countries - they are less easily appropriated than cash transfers, directly improve quality of life, generate education and income externalities, are likely to be cost-effective and have built-in tendencies towards being self-sustaining.

2. Since infectious diseases are most prevalent amongst the poor and children, their prevention and cure can lead to persistent reductions in health inequalities and thereby socioeconomic inequalities. However, the design of institutions and, in particular, equal opportunities for investing in schools and labour markets mediate this process.

3. The TRIPS agreement can be relaxed in favour of an alternative feasible regime such as the Health Impact Fund, which would incentivize pharmaceutical R\&D without aggravating health inequalities.

\section{Selected key reading}

1. Acemoglu D, Johnson S. Disease and Development: The Effect of Life Expectancy on Economic Growth. December 2007. Journal of Political Economy 115, pp. 925-985. 
2. Almond D, Currie J. Killing Me Softly: The Fetal Origins Hypothesis Journal of Economic Perspectives. 2011a;25; 153-172.

3. Bhalotra, S. and A. Venkataramani. Shadows of the Captain of the Men of Death: Early Life Health, Human Capital Investment and Institutions. Mimeograph at www.efm.bris.ac.uk/ecsrb/bhalotra.htm

4. Cunha, F. and J. J. Heckman. 2009. "The Economics and Psychology of Inequality and Human Development." Journal of the European Economic Association, Volume 7(2): 320-364.

5. Hollis, Aidan and Thomas Pogge. "The Health Impact Fund: Making New Medicines Available for All." Incentives for Global Health 2008: Oslo and New Haven. www.healthimpactfund.org

6. Kyle, Margaret K. and Anita M. McGahan. 2012. "Investments in Pharmaceuticals Before and After TRIPS" The Review of Economics and Statistics, prep-publication available at www.mitpressjournals.org/doi/abs/10.1162/REST_a_00214.

7. Pogge T. 2004. Relational Conceptions of Justice: Responsibilities for Health Outcomes. In Public Health, Ethics, and Equity, edited by Sudhir Anand, Fabienne Peter, and Amartya Sen, 135-161. Oxford: Clarendon Press. 